
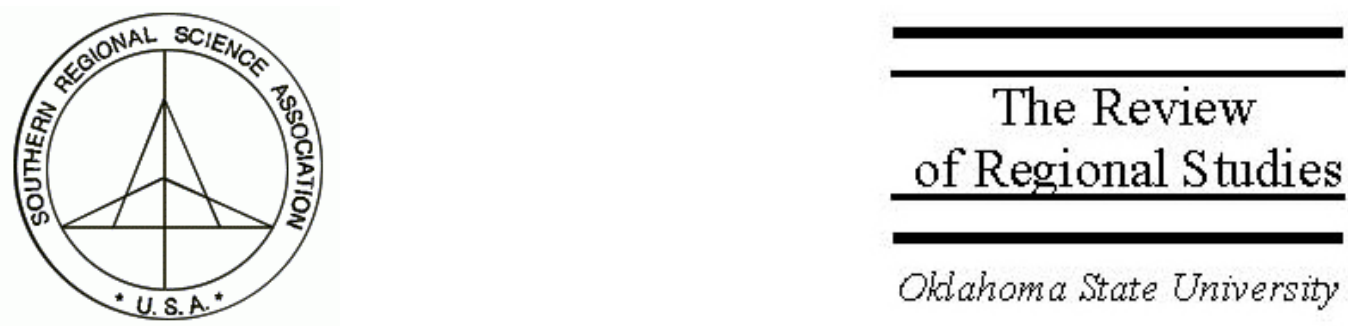

\title{
R\&D Investments and the Spatial Dimension: Evidence from Firm Level Data
}

\author{
Luisito Bertinelli \\ CREA, Université du Luxembourg, 162A, avenue de la Faïencerie, L-1511 Luxembourg, \\ e-mail: Luisito.Bertinelli@uni.lu
}

\section{Rosella Nicolini}

Instituto de Análisis Económico - CSIC, Campus de la Universitat Autònoma de Barcelona, 08193 Bellaterra (Barcelona), Spain, e-mail: rosella.nicolini@uab.es

\footnotetext{
Abstract

This paper proposes to investigate the effect of spillovers on firms’ R\&D investment decisions. We develop an analysis merging the geographer's toolbox with standard econometric techniques. For a chosen sample of sectors, we test the existence of positive spatial autocorrelation at the level of $R \& D$ investments. We provide results on how far the local environment may influence the firms' investment decisions, hence to what extent localization economies matter for agglomeration. Data confirm that the proximity to other firms investing in $R \& D$ may produce positive externalities. Finally, the diversity versus specialization debate is tackled.

Keywords: Local clustering; R\&D investment; Spatial autocorrelation

JEL classification: C23; L20; R12

We thank C. Dujardin, J. Le Gallo, E. Strobl, J.F. Thisse, and the participants of the XVIII EARIE Conference, The North American Summer Meeting of the Econometric Society (Los Angeles), 57 ${ }^{\text {th }}$ ESEM conference as well as LASERE seminar (CORE) for useful comments and suggestions. We thank also two anonymous referees and D. Rickman for their suggestions. We are grateful to Mr. Peter Teirlinck from Services fédéraux des affaires scientifiques, techniques et culturelles (SSTC) for providing us with the R\&D database. The second author research is supported by Ramón y Cajal contract of the Spanish Ministerio de Ciencia y Tecnología and by Barcelona Economics Program of CREA. All remaining errors, of course, are our own responsibility.
} 


\section{INTRODUCTION}

Different theories of agglomerations have been proposed. Most of them principally enlighten the importance of macroeconomic features that drive the location choices of firms (see Fujita, Krugman, and Venables 1999). As a consequence, these theories often tend to neglect that the sources of agglomeration may also stem from the direct interaction among firms themselves that belong to a specific location. Proximity helps to build direct as well as indirect interactions among firms. The approach concentrating on the micro-foundations of the spatial agglomeration (see Saxenian 1994 for a case study approach) builds around the presence of positive externalities such as local spillovers. ${ }^{1}$

The issue of detecting and measuring spillovers has a longstanding tradition in economics. Ever since Marshall's (1890) industrial districts, all kinds of spillovers (externalities) have been postulated. The main characteristic attributed to spillovers is their non-market nature, hence making their detection cumbersome.

In a recent survey, Audresch and Feldman (2004) resume the notion that most of the literature devoted to this kind of analysis is based on a central outcome: the importance of geographic proximity for spillovers is dependent on the propensity of similar industrial activities to agglomerate geographically. These basic terms of the debate are summarized in Audretsch (2003) as follows. The concentration (agglomeration) of firms within a spatial unit promotes knowledge spillovers between firms. However, a dichotomy rises since it could be that only firms belonging to the same industry can take advantage of these effects (specialization), but it can also happen that exchanges of complementary knowledge can take place even across different firms in different industries (diversity). These two concepts, specialization and diversity, also drive another debate aimed at stating the importance of the spillover effect generated in the same industry or those flowing from others. In this respect, various studies aim at determining which of the two prevails, or put differently, analyzing the effects of urbanization or localization economies when they appear.

In this paper, our aim is to provide a contribution intended to highlight interrelations between the spreading of spillovers and the spatial dimension, so as to lead firms to select some preferred areas in which to locate. Indeed, in order to stress the importance of local spillovers at the firm level, we analyze the extent to which the local environment affects firms’ R\&D investment choices. Hence, we do not focus on firm problems related to $\mathrm{R} \& \mathrm{D}$ as a mere industrial activity (financing, property rights, firm competition, and so on) and we skip from accounting any possible effect that R\&D investment can exert on firm performance.

\footnotetext{
${ }^{1}$ An example of a study that deals with this topic, in particular the interaction across firms (above all considering localization and urbanization economies) with plant data for U.S. is proposed by Henderson (2003). Other references can be found in Rosenthal and Strange (2004).
} 
To our knowledge, our study is one of the first attempts to apply spatial techniques for analyzing the spatial concentration of activities in a European country (namely Belgium). Our aim is twofold: (i) analyzing the spatial distribution of R\&D activity across Belgian districts by determining the varying propensities to cluster across several sectors, and (ii) determining the impact of urbanization and localization economies on R\&D investment decisions.

Departing from the hypothesis of an aspatial economy, we suppose that knowledge embodied in R\&D activities is subject to distance decay effects, making spillovers localized. This assumption principally grants to the contents of various recent contributions that we will discuss in the next subsection. Compared to other studies in innovation economics (for instance, Audretsch 1998), our approach pays more attention to the geographic component in drawing the existence of clusters of firms investing in R\&D. In this respect, in the first part of the study we provide some descriptive statistics aimed at enhancing the geographical dimension of the topic with which we are dealing. To that end, we have recourse to the geographer's toolbox in order to see whether the district dimension fits as a measure of R\&D externalities for our sample of firms. ${ }^{2}$ In other words, we assess whether districts are somehow self-contained in terms of R\&D. This outcome will allow us to determine more properly the extent to which knowledge may flow across geographic space. In the second part, we turn our attention towards the way R\&D proximity and related scale economies favor $R \& D$ investment intensity. We choose to concentrate on the dichotomy, specialization versus diversity (or similarly, localization versus urbanization).

Our approach basically differs from previous studies in this field by building the analysis on density variables. Indeed as pointed out by Ciccone and Hall (1996), there exists a direct linkage between density and proximity: higher density of economic activity will enhance productivity. Rearranging the assumption of these authors to our framework, we attempt to determine whether the spatial density of $R \& D$ investment is really able to affect the R\&D effort of each firm taken individually.

Our results support the idea that clustering of R\&D activity sustains R\&D investment. We are able to highlight that some districts are more specialized, ${ }^{3}$ whereas others tend to have a broader economic activity. As a corollary, we are able to detect sectors that display sensitivity to urbanization economies in the Belgian case.

\footnotetext{
${ }^{2}$ To make a useful comparison, a Belgian average district size is about a quarter of the smallest U.S. state, Rhode Island (about 2,700 skm) and slightly smaller than New York City (about 800 skm).

${ }^{3}$ By specialization we mean the propensity of a district to display high rates of R\&D investment only in one or a few sectors.
} 


\subsection{Related Literature: Spillovers versus Localization and Urbanization Effects}

It is widely recognized that proximity matters for making information circulate. As argued by Arrow (1962), tacit knowledge of a non-rival nature can easily spill over and be exploited in various economic applications. Hence, being close to an external source of information increases the impact of spillovers from that source.

According to Audretsch and Feldman (2004), the evolution of this topic followed different paths in European and, generally, North American literature across time. The North American literature puts the emphasis on the way high technology and knowledge spillovers spread across industries, while European literature focuses more on the role of networks and clusters in fostering the viability of small and medium enterprises above all in traditional industries. Therefore, the original idea of relating spillovers with localization and urbanization theory has been tackled quite a lot in studies produced mainly in the U.S.

In the early 1990s, Glaeser, Kallal, Sheinkman, and Shleifer (1992) and Henderson, Jaffee, and Trajtenberg (1995) made an important contribution to this literature by extending the debate on localization versus urbanization to a dynamic framework. Specifically, localization economies are the result of economic interactions within a given sector, while urbanization economies are fostered by the economic interactions across sectors. As a consequence, diversity favors spillovers according to the first authors, whereas the second authors argue that concentration of an industry within a city promotes knowledge spillovers and facilitates innovative activity.

Audretsch and Feldman (1996), Feldman and Audretsch (1999), and Audresch (2003) raise a similar question in the specific case of innovation activities rather than all production activities. The empirical evidence proposed in the first study suggests that industries in which knowledge inputs play a central role tend to cluster for exploiting the benefits issuing from tacit knowledge flows. ${ }^{4}$ Moreover, they set out that spatial clusters mainly result from the rise of new economic knowledge rather than solely from the concentration of production. In their second contribution, these authors explicitly tackle the problem of diversity vis-à-vis specialization and highlight that as in Jacobs (1969), science-based diversity is more conducive to knowledge spillovers, rather than diversity per se. Identifying the three sources of economic knowledge with $\mathrm{R} \& \mathrm{D}$, skilled labor, and size of the pool of basic science, these authors conclude that the location of production is expected to be more concentrated in those industries where knowledge spillovers are relevant, i.e., $R \& D$ intensive industries.

Various components that may spur knowledge spillovers have been detected. Audretsch (1998) argues that this role may be played by local institutions (e.g.,

\footnotetext{
${ }^{4}$ This argument takes its roots in a basic idea presented by Marshall (1890) and taken over later by Krugman (1991), according to which information flows and knowledge spillovers may be sensitive to geographic obstacles.
} 
universities, trade associations, local business organizations, etc.) providing technical and financial services that (i) firms cannot afford individually and (ii) make them collaborate. In addition, Fingleton (2003) discusses the importance of properly defining a framework for local spillovers (intra or inter regions), in particular if the study of local spillovers has to be used to draw some conclusion with a strong macroeconomic taste such as to state their role in regional growth as well as the regional catching-up process.

Rosenthal and Strange (2001, 2003) provide two interesting studies related to the nature of the agglomeration and spillovers. They argue (2001) that proxies for knowledge spillovers positively affect agglomeration only at the zip code level (in the U.S.), while manufactured inputs or natural resources do so at the national level. In addition, studying spillovers from an empirical viewpoint should be done at the city level. They state that at the county level, innovation from firms with more than 500 workers is nearly insignificant while at the zip code level it is positive and significant. (Indirectly this proves that knowledge spillovers attenuate rapidly.) They suggest also that knowledge spillovers contribute to agglomeration at the local level, especially when innovative activity is based on large and well-established firms. Rosenthal and Strange (2001) state also that the type of inputs upon which an industry depends influences the propensity to agglomerate. A reliance on manufactured inputs contributes to agglomeration, while a reliance on services does not, maybe because these inputs are produced under constant returns or are not industry-specific and hence are available everywhere.

In Rosenthal and Strange (2003), the authors extend the previous results and address the geographic and organizational nature of the agglomeration by examining the birth of new establishments and employment with respect to the employment level they choose. Basically they assume that if agglomeration economies are present, then births will occur near concentrations of existing employment, all else equal, whereas they tend to disperse if agglomeration economies are absent. The principal result of this study is to demonstrate that agglomeration economies attenuate with distance, and it confirms that agglomeration effects (hence spillovers) should be studied at a much finer geographic level. In addition, according to their statistics, for all the establishments in their sample, localization effects are more important than urbanization effects since the magnitude of their coefficient is larger. The ability to share both intermediate inputs and specialized labor are expected to be positive and diminish monotonically. ${ }^{5}$

In the same spirit, in a study dealing with the German case, Bode (2004) argues that low levels of R\&D support spillovers effect across regions, but distance smoothes spillover effects: less than 20 percent of knowledge spread over a distance requiring more than a 30-minute car ride, even if less innovative regions seem to be more receptive to benefit from interregional knowledge spillovers. ${ }^{6}$ Henderson (2003) provides a complete

\footnotetext{
${ }^{5}$ It is worth mentioning that both studies also establish that small firms are more productive than larger and these results enhance the attractiveness of locations principally composed of small plants.

${ }^{6}$ Similar results can be found in Viladecans-Marsal (2004) for the Spanish case.
} 
analysis on the sectors that seem to be more reactive to local spillovers and partially supports results by Rosenthal and Strange (2003).

According to Henderson (2003), if an industry is subject to localization economies, producers are likely to cluster in a few destinations since specialization allows exploiting economies of scale. In the case of Jacobs' (1969) (urbanization) economies, firms usually choose a larger local environment. Relating this pattern to the product cycle type, experimental activity (namely, innovative products) is found in large cross-fertilizing areas while standardized production is concentrated in more specialized locations. Concentrating on two main sectors in the U.S. (evaluated as standardized production), high-tech and machinery, he finds that high-tech plants benefit from their own present and past industry activity. He does not find any evidence for urbanization economies. Therefore, in his study, high-tech industries are substantially more agglomerated than machinery industries.

Finally, Cohen and Morrison (2005) propose an interesting study by which they link spillovers with location theory. Locating a firm in close proximity to similar types of firms or suppliers/demanders may have economic motivations in terms of fostering productivity or reducing costs. At the same time, reducing costs has exactly the same effect as spillovers. Hence, the implied agglomeration economies across firms may be due to various factors, among them information or knowledge spillovers. Spillovers shift factors that affect cost-output relationships and thus economic performance and competitiveness. In detail, Cohen and Morrison (2005), concentrating on U.S. food producers, replicate the previous results: localization economies from labor or other specialized input markets and knowledge spillovers turn out to be significant and help reduce production costs, while urbanization economies (which in their model arise from concentration on the demand side) exert the opposite effects, namely they increase the marginal costs in areas of high consumer demand and lower it in rural areas.

\subsection{Basic Issues}

One of the main outcomes of the empirical analysis dealt with in this branch of research is to provide statistically significant results at the micro level. Along with historical reasons, most of the authors exploit U.S. data because the quality of these data is usually suitable for this purpose.

Unfortunately, the availability of data at the micro level is not so common in Europe, and this situation limits the extension of this kind of analysis. In Europe, data limitations often prevent exploring this kind of issues within smaller geographic units than nations or regions. As argued by Wallsten (2001), in Europe we know that firms tend to cluster in certain regions so as to benefit from knowledge spillovers. Nevertheless, the possible relationship between the distance among firms and the strength of spillovers remains to be explored. 
In this study, we make an attempt to detect to what extent we are able to replicate the outcomes related to urbanization and localization economies in Europe, particularly in Belgium.

The general problem tackled throughout this paper is visually synthesized in Figure 1 where we have plotted the density function of aggregate R\&D density of Belgian firms in our sample across Belgian districts. It is straightforward to observe that firms investing in $\mathrm{R} \& \mathrm{D}$ are not uniformly spread across space. They polarize around a few locations, highlighting a high density of R\&D, while most other districts have low ones, thus suggesting that the geographic distribution of $R \& D$ activity is far from random.

The five most intensive districts in $R \& D$ represent about 15 percent of total Belgian land area but 68 percent of total Belgian R\&D. This skewed distribution does not, however, tell us whether high density R\&D districts tend to be close to one another. A supplementary question that is taken up is directly related to the decision of individual firms to invest in $\mathrm{R} \& \mathrm{D}$, according to their location in high respectively low density districts. Hence, our idea is to investigate and qualify the Belgian sectors in which spillovers are related to localization economies and drive the emergence of local agglomerations.

The remainder of the paper is organized as follows. Section 2 reviews the data we use as well as the indices of global and local spatial autocorrelation. In Section 3, firmlevel econometric specifications are run, aimed at detecting the impact of agglomeration economies on R\&D investment decisions. Finally, Section 4 concludes.

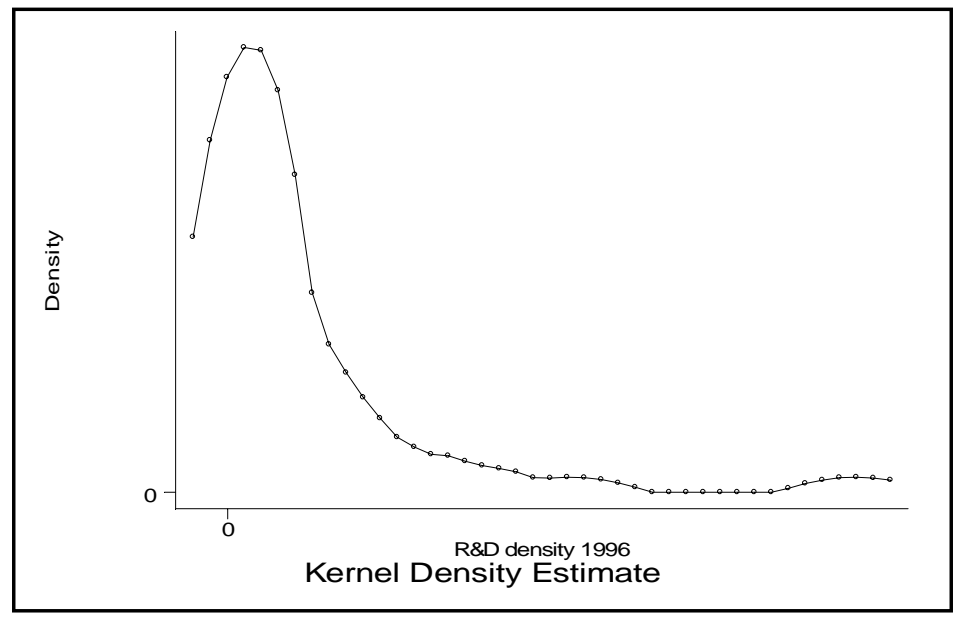

FIGURE 1: Kernel Distribution of R\&D Density in Belgium in 1996 (Estimation by Gaussian Kernel) 


\section{DATA AND SPATIAL INDICATORS}

Our data set consists of a panel of 1,637 Belgian establishments, including 48 of twoand three-digit NACE-BEL sectors spread across all 43 Belgian districts, the administrative area to which we refer. These units measure, on average, $709 \mathrm{sqm}$, and they represent an administrative geographic unit between the urban and the regional level. These data belong to the "Enquête R\&D 1998" commissioned by SSTC. It is a stratified (by sector and by district) sample of the total Belgian establishments ${ }^{7}$ that declared an intention to invest permanently or regularly in R\&D. It accounts for their R\&D expenditures in 1996 and 1997. This was a pilot experience for drawing a first portrait of the distribution of R\&D activity in Belgium.

As mentioned above, we have information at the establishment level. For each entry in the database, we know the zip code (which we aggregate in order to match the correspondent district unit), the sector of activity, the number of workers employed in the establishment in 1996 and 1997, as well as yearly revenues. We also have information about the exact amount of money invested annually in R\&D activities in 1996 and 1997 for a sub-sample of establishments. The $R \& D$ variable accounted for all the funds invested directly by firms, whither for their own projects or co-operation projects. In general, firms succeed in financing their R\&D activity either via their own cash flows or requesting financial support from regions at advantageous conditions. For confidentiality reasons, we do not have any other information related to the identity of the firm, but we are still able to distinguish them according to their size. In this section, we provide some general statistics to describe the information we have in our database for Belgian firms and provide some statistics highlighting interesting geographic patterns of agglomerations of Belgian firms investing in $R \& D$, thus, pointing to potential urbanization as well as localization economies.

\subsection{Basic Descriptive Statistics}

All firms included in our database are classified by sectors, according to the NACEBEL classification (two or three digits). We carry out a preliminary selection of our data to keep in our sample only sectors with a sufficiently large number of firms involved permanently in R\&D activities. According to the information available and the average observations per year and sector we dispose, we only keep the sectors that have at least 50 observations across our 43 districts. $^{8}$ Accordingly we selected a list of 21 sectors (see Table 1).

\footnotetext{
${ }^{7}$ This sample was collected by the Belgian SSTC (Services fédéraux des affaires scientifiques, techniques et culturelles) for the R\&D survey 1998. We engaged in preserving the confidentiality of the data.

${ }^{8}$ In this way, we avoid considering sectors with a reduced number of observations (given our geographic reference) for which they could suffer from problems of statistical significance.
} 
A few descriptive statistics can help to give the flavor of the contents of our database. In Table 1, we present simple statistics describing the average size of the establishments in our sample by sector. These statistics support the idea that the establishments included in the sample, with a few exceptions, are mostly display a medium-large size. In addition, by plotting the geographical distribution of establishments belonging to our sample in Figure 2, we are able to observe the way they spread across the districts (for all sectors aggregated).

The following map aims to describe a rough geographical concentration (at the district level) of Belgian establishments investing in R\&D. We obtained figures used in the map by looking at the proportion of establishments investing in R\&D by district as a percentage of total establishments investing in $R \& D$.

TABLE 1

Descriptive Statistics: Average Size of the Establishment per Sector (1996)

\begin{tabular}{clc}
\hline 2 Digits & & $\begin{array}{r}\text { Number } \\
\text { of hired } \\
\text { workers }\end{array}$ \\
\hline 15 & Manufacture of foodstuffs, alcohol and tobacco & 249 \\
17 & Production of textiles, clothing, leathers and shoes & 263 \\
22 & Paper and paper board industry, publishing and printing house & 223 \\
24 & Chemical industry & 263 \\
25 & Manufacturing of rubber and plastic products & 271 \\
26 & Production of other non-metallic mineral products & 165 \\
28 & Metallurgy and manufacture of metal products & 126 \\
29 & Manufacture of machines and equipment tools & 208 \\
31 & Manufacture of electrical and electronic equipment and & 361 \\
& instruments & \\
32 & Manufacture of radio, TV and communication tools & 576 \\
33 & Manufacture of clocks, medical care tools and other precision & 97 \\
34 & instruments & \\
45 & Manufacture of means of transport & 558 \\
50 & Constructions & 148 \\
70 & Real estate industry of transport & 143 \\
72 & Computer and data processing industry & 121 \\
73 & Research and Development (service) & 101 \\
75 & Public Administration and Social services & 6 \\
$\mathbf{3}$ Digits & & 68 \\
\hline 244 & Pharmaceutical industry & \\
271 & Iron industry & 248 \\
722 & Software industry & 1,191 \\
\hline Source: & Enquête R\&D 1998, Authors' calculations & 258 \\
\hline
\end{tabular}




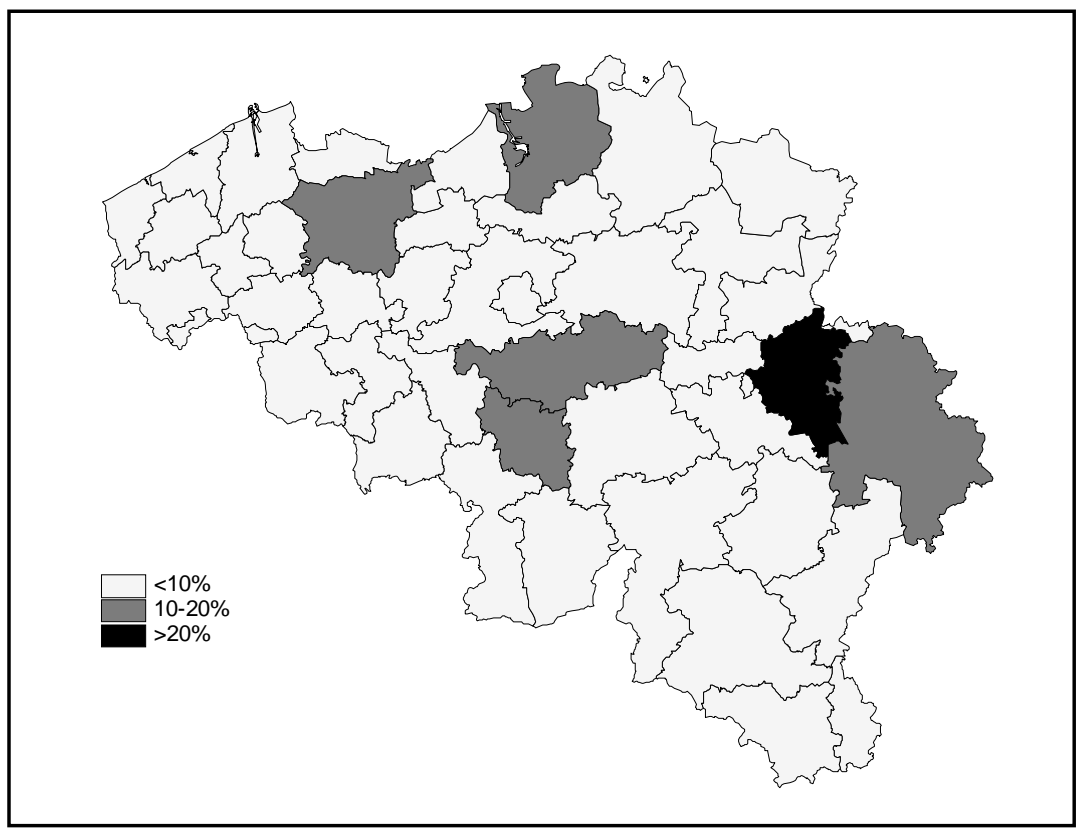

FIGURE 2: Spatial Concentration of Establishments Investing in R\&D (1996)

(Source: Enquête R\&D 1998)

This picture shows a tendency of establishments investing in R\&D to partially concentrate in the north, in the center, and in the east part of the country. This figure also discloses that there exists some pole of concentration of R\&D investing firms in Belgium, but it does not provide any information about the causes, i.e., we cannot $a$ priori argue that it is due to the existence of localization or urbanization economies. Note that this distribution could be strictly related to other factors, such as labor pooling as well as political/administrative reasons rather than $R \& D$ spillovers. In order to further investigate this issue, we compare this map with the one describing the density of total employment. (See Figure 3, displaying total employment by skm.) We easily realize that there is no strong correlation between spatial distribution of establishment investing in R\&D and employment density.

Labor is mainly concentrated in the northern districts. The highest concentration is in the center and corresponds to the geographic unit of Brussels (the Belgian capital and the headquarters of the European Union), which also corresponds to a political/administrative component, naturally attracting people. Moreover, by comparing Figures 2 and 3, it also emerges that Brussels district does not gather a strong concentration of establishments, while it does for labor. 


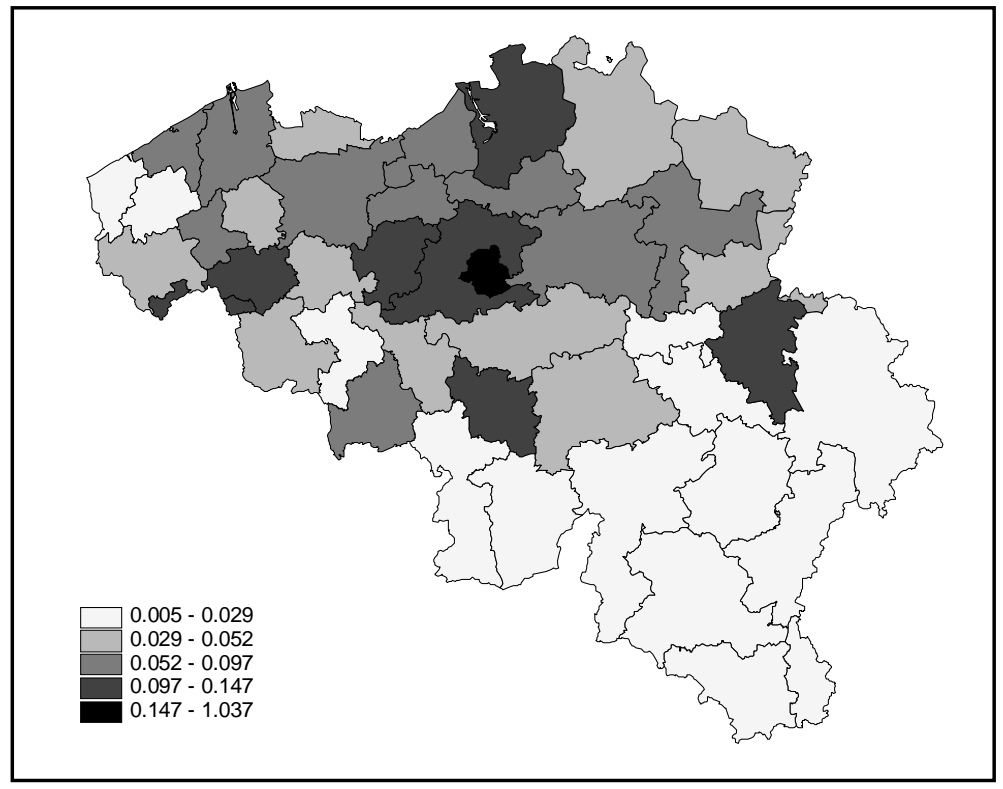

FIGURE 3: Total Employment Density (1997)

(Source: ONSS)

Hence, excluding Brussels, we may deduce that the propensity of Belgian establishments (of our sample) investing in $R \& D$ to concentrate in a few locations is relatively independent of the density of the workforce. Indirectly the emergence of agglomerations of those establishments can be due to reasons other than labor pooling, among which we include the localization and urbanization economies for which we are looking.

\subsection{Spatial Statistics}

In order to better qualify the geographic dimension of the data we have at our disposal and to see the propensity of establishments investing in R\&D to settle in proximity to other establishments of the same sector or other complementary sectors, we provide in the sequel results for spatial autocorrelation indicators. The spatial autocorrelation is the phenomenon where locational similarity (observation in spatial proximity) is matched by value similarity (attribute concentration) (Anselin, 1995). This means checking for the non-statistical independence of observations. Clusters of events, people, and facilities are referred to as "positive spatial autocorrelation," whereas "negative spatial autocorrelation" refers to arrangements where people, events, or facilities are dispersed. The aim is to detect whether there is a deterministic character in the location of economic activity, corroborating the polarized distribution of firms displayed in Figure 2.

A number of formal statistics attempt to measure spatial autocorrelation. Among those, Moran's I statistic and Geary's $C$ statistic are probably the most popular ones. We 
selected Moran's I (Moran, 1950) ${ }^{9}$ because it is the most common and is reputed to be slightly more robust. This statistic compares the value of a continuous variable at any location with the value of the same variable at surrounding locations. Values of Moran index significantly higher than the expectation of Moran's statistic will denote positive spatial autocorrelation. In other words, similar values, either high or low, are more spatially clustered than could be caused purely by chance.

The Moran index is computed for two: the former is the number of workers hired in each plant investing in R\&D (labeled Labor), and the latter is total expenditures in R\&D at the plant level. From a strictly technical viewpoint, in dealing with Moran statistics we do not account for the raw data but for the density data per sector and district, and we exclude Brussels districts as well. The rationale of this choice is the following: we are looking for factors confirming the propensity of Belgian establishments investing in $\mathrm{R} \& \mathrm{D}$ to agglomerate. In particular, we are interested in detecting whether these "factors" are local spillovers and then qualifying whether such spillovers arise from the R\&D activity of other establishments in the same sector or in other sectors. The basic general statistics we provided above show a general tendency to cluster if we account for a measure of concentration (such as density), but they also highlight the puzzling feature related to Brussels (quite low establishment concentration joined with a high labor pool). In such a case, considering also that Brussels is a very important political and administrative center for Belgium and the European Union, it seems reasonable to think that the concentration of establishment in such an area is principally due to motivations that do not precisely coincide with those we are looking for. Therefore, we exclude this district from the sample.

\subsection{The Moran Index}

As already mentioned, Moran's $I$ is a global statistic in the sense that only spatial autocorrelation of all the observations is accounted for, but it does not enable us to assess the contribution of every single observation. On the contrary, local measures of spatial autocorrelation are supposed to account for this drawback by measuring whether there are local spatial clusters of high or low values and detecting atypical localization.

We use both employment and R\&D as measures to compute spatial autocorrelation. Given our data availability, only the former measure allows us to take account of the whole sample. We can peg an interesting economic meaning to the statistics computed alternatively with the two values. The Moran $I$ computed with R\&D intuitively discloses information related to strictly research activity at the level of the establishment, while that computed with labor provides an indirect measure of the production activity under the assumption that a higher level of production corresponds to a higher number of employees.

\footnotetext{
${ }^{9}$ Moran statistics were carried out with the SpaceStat 1.90 software package (Anselin 1999).
} 
The results of Moran's I are displayed in Table 2. They are based on row standardized weighting matrices (based on a squared distance matrix by which we enhance the importance of proximity since we charge less weight to the most remote locations). Spatial autocorrelation for R\&D expenditures and the labor in 1996 and 1997 has been tested. Only statistically significant values are accounted for (darkened cells).

These outcomes confirm that spatial autocorrelation seems to be the rule rather than the exception in the case of Belgian firms investing in R\&D. Out of 21 sectors, nine highlight a positive spatial correlation for labor, contradicting the assumption of random distribution. Note however, that we cannot infer that the remaining 11 sectors are randomly distributed across space with respect to our choice of spatial unit, significance criterion, and data availability.

\section{TABLE 2}

Moran's I Statistics, Density Variables - Brussels Excluded Distance-Based (1/d $)$, Row-Standardized Weighting Matrix; Years 1996-97

\begin{tabular}{|c|c|c|c|}
\hline 2 Digits & & Labor & $R \& D$ \\
\hline 15 & Manufacture of foodstuffs, alcohol and tobacco & & \\
\hline 17 & Production of textiles, clothing, leathers and shoes & & \\
\hline 22 & Paper and paper board industry, publishing and printing house & & \\
\hline 24 & Chemical industry & & \\
\hline 25 & Manufacturing of rubber and plastic products & & \\
\hline 26 & Production of other non-metallic mineral products & & \\
\hline 28 & Metallurgy and manufacture of metal products & & \\
\hline 29 & Manufacture of machines and equipment tools & & \\
\hline 31 & $\begin{array}{l}\text { Manufacture of electrical and electronic equipment and } \\
\text { instruments }\end{array}$ & & \\
\hline 32 & \multirow{2}{*}{$\begin{array}{l}\text { Manufacture of radio, TV and communication tools } \\
\text { Manufacture of clocks, medical care tools and other precision } \\
\text { instruments }\end{array}$} & & \\
\hline 33 & & & \\
\hline 34 & Manufacture of means of transport & & \\
\hline 45 & Constructions & & \\
\hline 50 & Commerce of means of transport & & \\
\hline 70 & Real estate industry & & \\
\hline 72 & Computer and data processing industry & & \\
\hline 73 & Research and Development (service) & & \\
\hline 75 & Public Administration and Social services & & \\
\hline \multicolumn{2}{|l|}{3 Digits } & & \\
\hline 244 & Pharmaceutical industry & & \\
\hline 271 & Iron industry & & \\
\hline 722 & Software industry & & \\
\hline \multirow{2}{*}{\multicolumn{2}{|c|}{ Significance criterion: }} & & \\
\hline & & & \\
\hline
\end{tabular}


By contrast, R\&D is positively autocorrelated across districts only in one sector. A reason that could, at first glance, explain this paradoxical result can come from the choice of the spatial unit of reference (i.e., Belgian districts have an average area of $709 \mathrm{skm}$ ). If we assume that Belgian districts are more or less self-contained from the point of view of research, it is possible that $R \& D$ investments would highlight spatial autocorrelation only for a finer spatial scale and thus it cannot be detected in the present study. In other words, this implies that R\&D activity might be subject to more localized spillovers than production activities.

Furthermore, our results support the idea that traditional manufacturing sectors, such as Textiles, Publishing, and Printing display the important spatial autocorrelation of innovating firms. The same happens for sectors belonging to the service category (excluding Public Administration) or high technological sectors such as the Computer and Data Processing or Software industries. By contrast, for sectors that exploit technologies at medium R\&D intensity, the location of activities is hardly spatially correlated. Special attention should be paid to the case of Means of Transports. In Belgium, as stressed by various studies (for instance, Cassiman and Veugelers 2002), this sector is mainly composed of an important number of multinational subsidiaries assembling final products. Those subsidiaries, which invest in R\&D according the strategic plans of their headquarters, do not display a strong positive spatial autocorrelation. On the contrary, the sector that is in charge of the Commerce of the Means of Transports shows a higher degree of spatial autocorrelation (although not significant at the 5 percent confidence level). According to Rosenthal and Strange (2003), this result should be due to the sharing or mobility of specialized labor or intermediate inputs among firms. Further results with different weighting matrices tend to support the outcomes previously discussed. ${ }^{10}$ In most cases, the statistical significance of indices we previously detected is reinforced, assessing for the non-randomness of the distribution of spatial activity.

In an agglomeration economy perspective, this could mean that externalities are much more localized in R\&D activity than production activity. Put differently, there are stronger distance decay effects in the former than in the latter. This may depend on the kind of externalities at work: knowledge spillovers for R\&D or labor pooling for production activity. In this respect, these results are in line with those proposed by Rosenthal and Strange (2003). So, we may conclude that R\&D is not distributed randomly across locations and districts seem to be an adequate unit of measure for R\&D spillovers, thus supporting the idea of self-containment of districts in terms of R\&D.

\section{CLUSTERING AND EXTERNALITIES}

The main results of the previous section confirm that the role of the spatial proximity is not negligible when one intends to highlight how the surrounding environment affects

\footnotetext{
${ }^{10}$ Tables with further results based on different spatial matrices are available from the authors upon request.
} 
a single firm's decision. Firms close to other firms that invest in R\&D are more likely themselves to invest in R\&D. Moreover, clustering allows firms to exploit positive externalities.

In order to assess for the interpretation of local clustering as an indirect measure of externalities between firms, we ran an empirical investigation. As we discussed in the introduction, one of the advantages that firms can exploit by clustering is the reciprocal exploitation of the spillovers related to their activity. Spillovers (via external economies) reinforce the increasing returns to scale of which a firm can take advantage when locating in an agglomeration. Geographical density seems to be the proper way to measure the possible relationship between $\mathrm{R} \& \mathrm{D}$ spillovers and agglomeration of establishments investing in $\mathrm{R} \& \mathrm{D}$.

In this part, we aim to build a theoretical framework and test it empirically in order to evaluate econometrically the way the existence of localization and urbanization economies affect the intensity of R\&D expenditure at the establishment level, after having detected (by the previous statistics) that the same forces are at work for supporting the rise of local agglomeration. Put differently, once we observed that localization economies support spillovers that affect the location choice of establishments investing in R\&D (spatial distribution), we would like to test whether those components also affect R\&D activity efforts by each establishment. ${ }^{11}$

In the sequel, we explicitly examine the idea whether the spatial density of firms investing in $R \& D$ is a force driving the amount of $R \& D$ expenditures of firms. In our setting, focusing on density implies also accounting for distance decay effects in the diffusion of spillovers. As has been presented by previous theoretical as well as empirical findings, this effect is stronger when firms are abundant and workers mobile (Ciccone and Hall 1996). Workers move from one establishment to another, information circulates, and spillovers arise. Indeed, a firm may benefit from the R\&D activity of other competitors not only by direct exchange of R\&D information, but also by the personal contacts employees may have. Thus, a higher density of workers means that it is more likely for a worker to get in touch with others and make information circulate easily. As a consequence, it is also reasonable to think of the frequency of the contacts among workers as an alternative way to foster spillover circulation as well as a way to reduce the amount of resources devoted to R\&D activity. We sketch a simple framework using a partial equilibrium approach.

The approach we propose hereafter grants much to Ciccone and Hall (1996) and Ciccone (2002). Basically, we posit the assumption that the externality depends multiplicatively on a particular measure of density. However, we qualify this assertion by assuming that spatial density has to be interpreted as a measure of externalities. To do so, we rely on the Cobb-Douglas functional form. As in the foregoing, R\&D expenditure

${ }^{11}$ We measure the R\&D effort as the percentage of R\&D spending over the total revenue as an index of the cash flow an establishment devotes to finance its own R\&D. 
and labor are the only production input. As in standard economic geography models, firms are considered as monopolistic competitors. We get the following equation.

$$
Y_{i}=A_{i}\left(L_{i}\right)^{\alpha} \quad \text { with } A_{i}=\left(R \& D_{i}\right)\left(E_{i}\right)^{\beta}, \quad \alpha, \beta>0,
$$

where $Y_{i}$ is the level of final output for a firm $i, L_{i}$ the demand for labor, and $A_{i}$ corresponds to the $R \& D$ component that can be split in two parts. Indeed, $R \& D$ as an input involves both the direct expenditure of the firms itself $\left(R \& D_{i}\right)$ and the spillover benefits it gets from surrounding firms $\left(E_{i}\right)$. This equation replicates the basic assumptions of the model in economic geography (Fujita, Krugman, and Venables 1999), in which all firms behave under the monopolistic competition assumption.

Replacing the terms in the previous equation we get:

$$
Y_{i}=\left(R \& D_{i}\right)\left(E_{i}\right)^{\beta}\left(L_{i}\right)^{\alpha} .
$$

Rearranging the terms of equation (1), we solve this expression for the per-firm investment in research and development. This indicator helps us to isolate the spillovers (Ei) effects.

The corresponding expression is given by: ${ }^{12}$

$$
\frac{R \& D_{i}}{Y_{i}}=E_{i}^{(-\beta)}\left(L_{i}\right)^{(-\alpha)}
$$

Once we assume the existence of the externalities, we define their main components as well. For the reasons mentioned above, we mainly concentrate on two measures of density: the former embodies R\&D activity at the firm level and the latter the density of workers $\left(D L_{a}\right)$. In this setting, employment and $R \& D$ expenditures are inversely related. As in the previous case, we distinguish between spillovers connected with the R\&D activity of firms in the same sector $\left(D_{r d a}\right)$, localization economies, and those of all firms in the same spatial area but in different sectors $\left(D_{r d s}\right)$, urbanization economies. ${ }^{13}$

\footnotetext{
${ }^{12}$ The parameters $\alpha$ and $\beta$ are constant. They embody the elasticity of each input with respect to the quota of R\&D over sales.

${ }^{13}$ The issue to relate a measure of firm density with R\&D density involving the presence of local spillovers has been provided in various studies. For instance, we can mention Lee (2003) for an empirical study on U.S. firms. From a strictly theoretical viewpoint, Meagher and Rogers (2004) propose an interesting way to model innovation or R\&D spillovers by using ideas from organizational theory. In addition, according to Ciccone and Hall (1996), measures of urbanization economies could in part capture the effects of omitted inputs (for instance, greater outsourcing of business services).
} 
Let us assume that externalities ( $E i)$ are the result of an existing trade-off between those densities (weighted by a parameter $\gamma_{t}$. To fit the previous equation to our assumptions, we define ( $\mathrm{Ei}$ ) as a combination of different measures of density in the following way:

$$
E_{i}=\frac{D^{\gamma_{1}} L a}{D^{\gamma_{2}}{ }_{r d s} D^{\gamma_{3}} r d a} \quad \gamma_{i}>0, \quad i=1,2,3
$$

Replacing (3) in (4) and rearranging the terms:

$$
\frac{R \& D_{i}}{Y_{i}}=\left(\frac{D^{\gamma_{2}} r d s D^{\gamma_{3}} r d a}{D^{\gamma_{1}} L a}\right)^{\beta}\left(L_{i}\right)^{-\alpha}
$$

and by taking logarithms, the previous expression becomes:

$$
\log \left(\frac{R \& D_{i}}{Y_{i}}\right)=\beta\left[\gamma_{2} \log \left(D_{r d s}\right)+\gamma_{3} \log \left(D_{r d a}\right)\right]-\beta \gamma_{1} \log \left(D_{L a}\right)-\alpha \log \left(L_{i}\right) .
$$

In our empirical test, we concentrate on equation (6). One of the basic features of that equation is that labor density detracts from R\&D density. Labor density means more interaction among workers and even more mobility, such as to create spillover effects within an industry that can partially replace the firm effort in terms of their own resources devoted to R\&D. Spillovers generate a sort of saving process at the firm level (as argued in Cohen and Morrison 2005). For our purpose, we aim to disentangle the effect that each kind of density may have on the R\&D effort (measured as by R\&D intensity) at the firm level. We propose two types of estimations. In principle, we look at how our sample of firms (taken as a whole) behaves vis-a-vis the detected trade-off between density and intensity. To this end, we deal with panel data estimations. Once we have detected the general trend of the sample, we concentrate on a selected number of sectors to isolate some details more related to each industry. Box 1 defines the variables we account for in our estimations.

In the first stage, we concentrate on the whole sample of firms in our database. The purpose of these estimations is to detect any possible relationship between R\&D intensity at the firm level (using a proxy of the ratio between the R\&D expenditure and the total sales of each firm) and the three different measures of $R \& D$ densities, hence the economy's supporting spillovers.

According to equation (6), the two R\&D densities ( $D_{r d a}$ and $D_{r d s}$ ) should exhibit a positive relationship with the $R \& D$ intensity. Indeed, they basically sum up the positive effects that R\&D spillovers of other firms exert directly on R\&D effort of the firm we account for. On the contrary, for the reasons mentioned before, labor density $\left(D_{l a}\right)$ is 
expected to be negatively related to the dependent variable. Indeed, supposing that externalities come from the concentration of $R \& D$ activity rather than from the general concentration of production activity, one may consider that labor concentration acts as a negative rather than a positive force. Hence, the labor variable is supposed to exhibit a negative coefficient. Relying on equation (6) for a given level of sales, a higher value of $\mathrm{Li}$ (as input) involves devoting fewer resources to R\&D.

\section{BOX 1}

\begin{tabular}{|c|c|c|}
\hline \multicolumn{3}{|l|}{$\begin{array}{l}\text { Correspondence } \\
\text { to equation (6) }\end{array}$} \\
\hline & Dummy96 & Dummy variable for year 1996 \\
\hline \multirow[t]{5}{*}{$\log \left(D_{r d s}\right)$} & LD & $\begin{array}{l}\text { In the pooled sample, logarithm of the density of R\&D } \\
\text { expenditure for all sectors except the sector we alternatively } \\
\text { account for by arrondissement }\end{array}$ \\
\hline & LD15 & $\begin{array}{l}\text { Logarithm of the density of R\&D expenditure for all sectors } \\
\text { except sector } 15 \text { by arrondissement }\end{array}$ \\
\hline & LD28 & $\begin{array}{l}\text { Logarithm of the density of } R \& D \text { expenditure for all sectors } \\
\text { except sector } 28 \text { by arrondissement }\end{array}$ \\
\hline & LD31 & $\begin{array}{l}\text { Logarithm of the density of R\&D expenditure for all sectors } \\
\text { except sector } 31 \text { by arrondissement }\end{array}$ \\
\hline & LD50 & $\begin{array}{l}\text { Logarithm of the density of R\&D expenditure for all sectors } \\
\text { except sector } 50 \text { by arrondissement }\end{array}$ \\
\hline \multirow[t]{5}{*}{$\log \left(D_{L a}\right)$} & LDL & $\begin{array}{l}\text { In the pooled sample, logarithm of the density of the labor } \\
\text { force for sector we alternatively account for by } \\
\text { arrondissement }\end{array}$ \\
\hline & LDL15 & $\begin{array}{l}\text { Logarithm of the density of the labor force for sector } 15 \text { by } \\
\text { arrondissement }\end{array}$ \\
\hline & LDL28 & $\begin{array}{l}\text { Logarithm of the density of the labor force for sector } 28 \text { by } \\
\text { arrondissement }\end{array}$ \\
\hline & LDL31 & $\begin{array}{l}\text { Logarithm of the density of the labor force for sector } 31 \text { by } \\
\text { arrondissement }\end{array}$ \\
\hline & LDL50 & $\begin{array}{l}\text { Logarithm of the density of the labor force for sector } 50 \text { by } \\
\text { arrondissement }\end{array}$ \\
\hline \multirow[t]{5}{*}{$\log \left(D_{r d a}\right)$} & LDRD & $\begin{array}{l}\text { In the pooled sample, logarithm of the density of R\&D } \\
\text { expenditure for sector we alternatively account for by } \\
\text { arrondissement }\end{array}$ \\
\hline & LDRD15 & $\begin{array}{l}\text { Logarithm of the density of R\&D expenditure for sector } 15 \\
\text { by arrondissement }\end{array}$ \\
\hline & LDRD28 & $\begin{array}{l}\text { Logarithm of the density of R\&D expenditure for sector } 28 \\
\text { by arrondissement }\end{array}$ \\
\hline & LDRD31 & $\begin{array}{l}\text { Logarithm of the density of R\&D expenditure for sector } 31 \\
\text { by arrondissement }\end{array}$ \\
\hline & LDRD50 & $\begin{array}{l}\text { Logarithm of the density of R\&D expenditure for sector } 50 \\
\text { by arrondissement }\end{array}$ \\
\hline $\log \left(L_{i}\right)$ & LLABOUR & Logarithm number of workers per firm \\
\hline $\log \left(\frac{R \& D_{i}}{Y_{i}}\right)$ & LRDCHAF & Logarithm of R\&D expenditures over total sales per firm \\
\hline
\end{tabular}


Table 3 reports the results of the estimation of equation (6) for the whole sample (Bertinelli and Nicolini 2002). We applied a panel data procedure with three different methods of estimation, by choosing as dependent variable (LRDCHAF) the quota of $R \& D$ expenditure over revenues (for each establishment) as a measure of the intensity of the R\&D effort. For all three methods, the outcomes are quite homogeneous and consistent. Whenever the density variables are significant, they display the expected coefficient. In particular, $L D R D$ is always positive and highly significant. This result confirms the role and the importance of positive spillovers for R\&D investment inside each sector (localization economies) in supporting the R\&D investing effort. Moreover, it also appears that spillovers coming from the $R \& D$ activities in other sectors (urbanization economies) do not seem to play any role. Indeed, the corresponding variable $(L D)$ is always negative or close to zero. To sum up, these results tend to support the importance of "specialization” versus "diversity” (localization versus urbanization). Put differently, according to these results we can argue that agglomeration of science and technology occurs within a sector rather than across sectors. These outcomes bear out the idea that in detecting the factors affecting establishment concentration, Belgium replicates the same patterns as described for the U.S. (Rosenthal and Strange (2001, 2003) and Henderson (2003)), in which localization economies prevail over urbanization economies.

TABLE 3

Econometric Results: Intensity Versus Density

\begin{tabular}{|c|c|c|c|}
\hline & Pooled & $\begin{array}{c}\text { Pooled } \\
\text { Sectoral Fixed Effects }^{14}\end{array}$ & $\begin{array}{c}\text { Within } \\
\text { Per Firm Fixed Effects } \\
\end{array}$ \\
\hline \multirow[t]{2}{*}{ Constant } & $-5.152^{* * *}$ & $-5.067^{* * *}$ & $-3.001^{* * *}$ \\
\hline & $(0.266)$ & $(0.890)$ & $(0.727)$ \\
\hline \multirow[t]{2}{*}{ Dummy96 } & $-0.197^{* *}$ & $-0.147^{*}$ & $-0.062^{*}$ \\
\hline & $(0.084)$ & $(0.080)$ & $(0.034)$ \\
\hline \multirow[t]{2}{*}{ LLABOUR } & $-0.398^{* * *}$ & $-0.344^{* * *}$ & $-0.032^{* * *}$ \\
\hline & $(0.028)$ & $(0.031)$ & $(0.112)$ \\
\hline \multirow[t]{2}{*}{$L D$} & 0.009 & -0.027 & 0.009 \\
\hline & $(0.023)$ & $(0.024)$ & $(0.063)$ \\
\hline \multirow[t]{2}{*}{$L D L$} & $-0.598^{* * *}$ & $-0.433^{* * *}$ & 0.318 \\
\hline & $(0.035)$ & $(0.039)$ & $(0.238)$ \\
\hline \multirow[t]{2}{*}{$L D R D$} & $0.703^{* * *}$ & $0.539^{* * *}$ & $0.123^{* * *}$ \\
\hline & $(0.028)$ & $(0.034)$ & $(0.038)$ \\
\hline Obs & 983 & 983 & 983 \\
\hline Adjusted $R^{2}$ & 0.49 & 0.54 & \\
\hline$R^{2} e:$ Within & & & 0.05 \\
\hline $\begin{array}{l}\text { Dependent Va } \\
\text { Method of Est } \\
\text { Value in Brack } \\
* * * * 1 \% \text { significa }\end{array}$ & $\begin{array}{l}\text { LRDCH } \\
\text { on: Variou } \\
\text { Standard E } \\
\text { level; }{ }^{* *} 5 \% \text {; }\end{array}$ & & \\
\hline
\end{tabular}

\footnotetext{
${ }^{14}$ The Fisher statistic for joint significance of the sector dummy rejects the null hypothesis.
} 
Nevertheless, we get these results without isolating particular sectors, while Rosenthal and Strange (2001, 2003) and Henderson (2003) do so. In fact, in our previous exercise, by considering the whole sample, a few cross-sector effects could hide other effects related to just one of a few sectors. Hence, the next step is to qualify the previous findings by providing sectoral estimations. Given the sample of data at hand, we concentrate on four particular sectors: Food and Beverages (15), Metallurgy (28), Electronic Equipment (31), and Commerce of Means of Transport (50). These sectors are quite heterogeneous, and each of them covers a range of peculiar features.

We repeat the same exercise as before but account for the heterogeneity between sectors. Looking at the results displayed in Table 4, one immediately realizes that sensitivity towards localization versus urbanization economies varies from sector to sector. Looking at the sign of the corresponding elasticities, sector 28 (Metallurgy) benefits more from inter-sectoral spillovers, while sector 31 (Electronic Equipment) more from intrasectoral ones. The same conclusion holds for sector 50 (Commerce of Means of Transport). Data for sector 15 (Manufacture of Foodstuffs, Alcohol and Tobacco) point out no spillover sensitiveness at all.

Turning to Table 5, we included fixed effects in our estimations in order to take account of unobserved heterogeneity among firms (given the structure of our panel). According to Henderson (2003), including per-plant fixed effects represents a way to disentangle the entrepreneur/manager's ability. Henderson argues that it is a way to deal with selectivity issues; and in case of sufficient variations in all variables, it is possible to make inferences about the effects of changes in the environment on productivity. Given the data at hand, we cannot deal with the second issue; hence we only concentrate on the first.

Working with fixed effect estimations except for sector 31, the significance of the coefficient of the variables mostly fails. Besides the small sample size, loss of significance may be partly due to the fact that our panel only entails two periods. The only significant result concerns sector 15 (Food \& Beverage), supporting the existence of localization economies but not urbanization ones. The same result holds for sector 31, where localization rather than urbanization prevails. Moreover, for this latter sector, diversity of $R \& D$ expenditure deters own $R \& D$ expenditure, pointing to possible crowding out effects. No straightforward conclusion can be drawn for sector 50 .

As a consequence, in the case we assume that firms are homogenous, sectoral estimations confirm that diversity and specialization are important in a few sectors (here, for instance, Chemical and Real Estate), while for Mechanical, only specialization plays an important role. The same kind of result holds even for a traditional sector such as Food and Beverage when accounting for heterogeneity among firms. Hence, at a sectoral level, our results confirm that localization economies are statistically important, but there are situations in which urbanization economies also matter for supporting the R\&D spending effort. 
TABLE 4

Econometric Results: Intensity Versus Density

\begin{tabular}{|c|c|c|c|c|}
\hline & Sector 15 & Sector 28 & Sector 31 & Sector 50 \\
\hline Constant & $\begin{array}{l}-6.609^{* * *} \\
(1.462)\end{array}$ & $\begin{array}{l}-4.210^{* *} \\
(1.610)\end{array}$ & $\begin{array}{l}-3.688^{* * *} \\
(1.013)\end{array}$ & $\begin{array}{l}-1.695 \\
(0.766)\end{array}$ \\
\hline Dummy96 & $\begin{array}{l}-0.013 \\
(0.362)\end{array}$ & $\begin{array}{l}-0.007 \\
(0.385)\end{array}$ & $\begin{array}{c}0.069 \\
(0.264)\end{array}$ & $\begin{array}{l}-0.221 \\
(0.274)\end{array}$ \\
\hline LLABOUR & $\begin{array}{c}0.048 \\
(0.218)\end{array}$ & $\begin{array}{l}-0.413^{* *} \\
(0.162)\end{array}$ & $\begin{array}{l}-0.404^{* * *} \\
(0.085)\end{array}$ & $\begin{array}{l}-0.586^{* * *} \\
(0.135)\end{array}$ \\
\hline LD15 & $\begin{array}{c}0.020 \\
(0.090)\end{array}$ & & & \\
\hline LD28 & & $\begin{array}{c}0.249^{*} \\
(0.137)\end{array}$ & & \\
\hline LD31 & & & $\begin{array}{l}-0.150 \\
(0.101)\end{array}$ & \\
\hline LD50 & & & & $\begin{array}{l}-0.273^{* * *} \\
(0.092)\end{array}$ \\
\hline LDL15 & $\begin{array}{l}-0.356^{* *} \\
(0.178)\end{array}$ & & & \\
\hline$L D L 28$ & & $\begin{array}{l}-0.206 \\
(0.281)\end{array}$ & & \\
\hline$L D L 31$ & & & $\begin{array}{l}-0.323^{* *} \\
(0.137)\end{array}$ & \\
\hline LDL50 & & & & $\begin{array}{l}-0.163 \\
(0.120)\end{array}$ \\
\hline LDRD15 & $\begin{array}{c}0.195 \\
(0.157)\end{array}$ & & & \\
\hline LDRD28 & & $\begin{array}{c}0.062 \\
(0.666)\end{array}$ & & \\
\hline LDRD31 & & & $\begin{array}{l}0.658^{* * *} \\
(0.140)\end{array}$ & \\
\hline LDRD50 & & & & $\begin{array}{l}0.512^{* * *} \\
(0.122)\end{array}$ \\
\hline Obs & 70 & 54 & 57 & 67 \\
\hline Adjusted $R^{2}$ & -0.02 & 0.09 & 0.37 & 0.47 \\
\hline \multicolumn{5}{|c|}{$\begin{array}{l}\text { Dependent Variable: LRDCHAF } \\
\text { Method of Estimation: OLS with White methodology for correcting heteroskedasticity } \\
\text { Value in Brackets: Standard Error } \\
{ }_{*}^{* *} 1 \% \text { significance level; }{ }^{* *} 5 \% ;{ }^{*} 10 \%\end{array}$} \\
\hline
\end{tabular}


TABLE 5

Econometric Results: Intensity Versus Density

\begin{tabular}{|c|c|c|c|c|}
\hline & Sector 15 & Sector 28 & Sector 31 & Sector 50 \\
\hline Constant & $\begin{array}{l}-4.200 \\
(2.614)\end{array}$ & $\begin{array}{l}-11.2940 \\
(13.4320)\end{array}$ & $\begin{array}{c}0.367 \\
(1.559)\end{array}$ & $\begin{array}{c}1.3510 \\
(1.6440)\end{array}$ \\
\hline Dummy96 & $\begin{array}{l}-0.274^{* * *} \\
(0.089)\end{array}$ & $\begin{array}{l}-0.1080 \\
(0.4760)\end{array}$ & $\begin{array}{c}0.204 \\
(0.262)\end{array}$ & $\begin{array}{l}-0.0742 \\
(0.1040)\end{array}$ \\
\hline LLABOUR & $\begin{array}{l}-1.105^{* * *} \\
(0.234)\end{array}$ & $\begin{array}{l}-0.0940 \\
(0.247)\end{array}$ & $\begin{array}{l}-0.300^{* *} \\
(0.122)\end{array}$ & $\begin{array}{l}-1.6030^{* * *} \\
(0.3370)\end{array}$ \\
\hline LD15 & $\begin{array}{c}0.356 \\
(0.349)\end{array}$ & & & \\
\hline$L D 28$ & & $\begin{array}{c}0.9250 \\
(1.774)\end{array}$ & & \\
\hline LD31 & & & $\begin{array}{l}-0.36^{* *} \\
(0.137)\end{array}$ & \\
\hline$L D 50$ & & & & $\begin{array}{c}0.0250 \\
(0.1440)\end{array}$ \\
\hline LDL15 & $\begin{array}{c}0.820 \\
(0.722)\end{array}$ & & & \\
\hline LDL28 & & $\begin{array}{l}-1.0650 \\
(1.7100)\end{array}$ & & \\
\hline LDL31 & & & $\begin{array}{c}0.586 * \\
(0.327)\end{array}$ & \\
\hline$L D L 50$ & & & & $\begin{array}{c}0.0380 \\
(0.0840)\end{array}$ \\
\hline LDRD15 & $\begin{array}{c}0.327^{*} \\
(0.167)\end{array}$ & & & \\
\hline$L D R D 28$ & & $\begin{array}{c}0.0199 \\
(0.2010)\end{array}$ & & \\
\hline LDRD31 & & & $\begin{array}{l}-0.102 \\
(0.304)\end{array}$ & \\
\hline LDRD50 & & & & $\begin{array}{c}0.1040 \\
(0.0760)\end{array}$ \\
\hline $\begin{array}{l}\text { Obs } \\
R^{2} \text { Within }\end{array}$ & $\begin{array}{l}70 \\
0.59\end{array}$ & $\begin{array}{l}54 \\
0.03\end{array}$ & 57 & $\begin{array}{c}67 \\
059\end{array}$ \\
\hline $\begin{array}{l}\text { Dependent V } \\
\text { Method of Es } \\
\text { Value in Bra } \\
* * * * 1 \% \text { signifi }\end{array}$ & $\begin{array}{l}\text { LRDCHAF } \\
\text { t: Panel esti } \\
\text { tandard Erro } \\
\text { vel; **5\%; }\end{array}$ & ith fixed e & firm & \\
\hline
\end{tabular}

\section{CONCLUSIONS}

In this study, we provide an empirical investigation on the spatial distribution of investments in $R \& D$ at the establishment level in the case of Belgium, focusing on the relationship between localization and urbanization economies in line with various studies conducted in the U.S. We mainly focus on the role that the geographic component (spatial distance) plays in affecting establishment decision in R\&D investment. To this 
end, we have recourse to the geographer's toolbox to draw a map of the spatial distribution of the R\&D activity for our sample of establishments. Given a sample of selected sectors, by computing Moran's I statistics we detected positive spatial autocorrelation for most sectors. This result suggests that the distribution of R\&D investment tends to be spatially dependent. As a consequence, we can easily deduce that innovation activity is not uniformly distributed across Belgium and several districts display a different technological specialization.

Once we posit the importance of the geographic dimension in firm investment choices, we extend our analysis by looking for the direct effect of localization and urbanization economies over R\&D efforts. In the second part of the analysis, we develop an econometric exercise where we concentrate on the specialization-diversity trade-off. Dealing with an econometric investigation on a sample of chosen sectors, we find that the specialization (localization) component positively affects the R\&D expenditures of establishments whenever the $R \& D$ contents are specific, whereas, in other cases, urbanization economies also matter.

Of course, it could be interesting to extend these results to other sectors of activity or even, other European countries. However, from a more local viewpoint, these results may allow some comments in policy matters. In Belgium as well as in other countries with important regional disparities, a spatial economic approach should help in drawing a map of the most performing or active firms (such as those who invest in R\&D) to try to sketch some possible regional growth paths. One way to proceed should be to account for the existence of technological incubators (such as universities or other centers of research) as centripetal poles for innovating activity. More generally, it should also help to test more precisely how the local environment may affect performance at the firm level. Belonging to dynamic regions and locating in existing clusters of activities is expected to be an important asset for firms, leading them to improve their economic performances.

\section{REFERENCES}

Anselin, L., 1995. "Local Indicators of Spatial Association-LISA," Geographical Analysis 27(2), 93-115. , 1999. SpaceStat, A Software Package for the Analysis of Spatial Data, Version 1.90. BioMedware: Ann Arbor.

Arrow, K., 1962. "Economic Welfare and the Allocation of Resources for Invention," in R. Nelson (ed.), The Rate and Direction of Innovative Activity. University Press: Princeton.

Audretsch, D.B., 1998. "Agglomeration and the Location of Innovative Activity," Oxford Review of Economic Policy 14(2), 18-29. , 2003. "Innovation and Spatial Externalities," International Regional Science Review 26(2), 167-174.

Audretsch, D.B. and M. Feldman, 1996. "R\&D Spillovers and the Geography of Innovation and Production,” American Economic Review 86(3), 630-640. 
, 2004. "Knowledge Spillovers and the Geography of Innovation,” in J. V. Henderson and J.F. Thisse (eds), Handbook of Regional and Urban Economics, Vol. 4, pp. 2713-2739.

Bertinelli, L. and R. Nicolini, 2002. "La R\&D au Niveau des Entreprises Belges: Une Approche Spatiale,” Cahiers Economiques de Bruxelles 45(4), 187-216.

Bode, E., 2004. "The Spatial Pattern of Localized R\&D Spillovers: An Empirical Investigation for Germany,” Journal of Economic Geography 4(1), 43-64.

Cassiman, B. and R. Veuglers, 2002. "R\&D Cooperation and Spillovers: Some Empirical Evidence from Belgium,” American Economic Review 92(4), 1169-1184.

Ciccone, A., 2002. "Agglomeration Effects in Europe," European Economic Review 46(2), 213-227

Ciccone, A. and R.E. Hall, 1996. "Productivity and the Density of Economic Activity," American Economic Review 86(1), 54-70.

Cohen, J.P. and P.C.J. Morrison, 2005. "Agglomeration Economies and Industry Location Decisions: The Impacts of Spatial and Industrial Spillovers," Regional Science and Urban Economic 35, 215-237.

Feldman, M. and D.B. Audretsch, 1999. "Innovation in Cities: Science-Based Diversity, Specialization and Localized Competition,” European Economic Review 43, 409429.

Fingleton, B., 2003. "Externalities, Economic Geography and Spatial Econometrics: Conceptual and Modeling Developments," International Regional Science Review 26(2), 197-207.

Fujita, M., P. Krugman, and A. Venables, 1999. The Spatial Economy. MIT Press: Cambridge.

Glaeser, E., H. Kallal, J. Sheinkman, and A. Shleifer, 1992. “Growth in Cities,” Journal of Political Economy 100, 1126-1152.

Henderson, J.V., 2003. “Marshall’s Scale Economies,” Journal of Urban Economics 53, $1-28$.

Henderson, R., A.B. Jaffe, and M. Trajtenberg, 1995. "Universities as a Source of Commercial Technology: A Detailed Analysis of University Patenting 19651985,” NBER Working paper N. 5068.

Jacobs, J., 1969. The Economy of Cities. Random House: New York.

Krugman, P., 1991. Geography and Trade. MIT Press: Cambridge.

Lee, C.Y., 2003. "Firm Density and Industry R\&D Intensity: Theory and Evidence," Review of Industrial Organization 22, 139-158.

Marshall, A., 1890. Principles of Economics (1920 Edition). MacMillan \& Company: London.

Meagher, K. and M. Rogers, 2004. “Network Density and R\&D Spillovers,” Journal of Economic Behaviour and Organization 53, 237-260.

Moran, P., 1950. “A Test for Serial Independence of Residuals,” Biometrika 37, 178181.

Rosenthal, S.S. and W.C.Strange, 2001. “The Determinants of Agglomeration,” Journal of Urban Economics 50, 191-229. , 2003. "Geography, Industrial Organization, and Agglomeration,” The Review of Economic and Statistic 85(2), 377-393. 
, 2004. "Evidence on the Nature and Sources of Agglomeration Economies," in J.V. Henderson and J.F. Thisse (eds.), Handbook of Regional and Urban Economics, Vol. 4, pp. 2713-2739.

Saxenian, A., 1994. Regional Advantage: Culture and Competition in Silicon Valley and Route 12. Harvard University Press: Cambridge, MA.

Viladecans-Marsal, E., 2004. “Agglomeration Economies and Industrial Location: CityLevel Evidence,” Journal of Economic Geography 4(5), 565-582,

Wallsten, S.J., 2001. “An Empirical Test of Geographic Knowledge Spillovers Using Geographic Information Systems and Firm-Level Data,” Regional Science and Urban Economic 31, 571-599. 